\title{
Long-term Survival of Cultured Adult Rat Heart Cells
}

\author{
Kazunari YAMANA, M.D.
}

\begin{abstract}
Summary
This paper reports several modifications of our previous culture

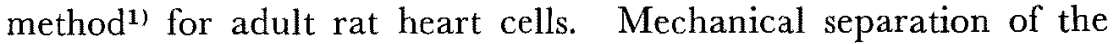
cells at $12 \mathrm{rpm}$ rather than $8 \mathrm{rpm}$ doubled the number of beating cells in the final culture medium. A $60 \%$ Ficoll-Paque solution was found to be optimal for exclusion of non-muscle cells such as endothelial cells and fibroblasts from the culture, followed by frequent medium exchange to eliminate traces of this reagent from culture medium. However, the presence of some non-muscle cells seemed to exert a positive effect on culture longevity. Eagle's MEM medium containing 20\% FBS resulted in maximum (over 50 days) survival of cultures.
\end{abstract}

\section{Additional Indexing Words :}

Adult rat Cardiomyocytes Culture

CINCE Vahouny et $a^{21}$ first described adult rat heart cell cultures in 1970, $\bigcirc$ many investigators have examined culture techniques. However, most studies could not prolong the viability of cultured adult rat heart cells over 24 hours. In 1977, Jacobson ${ }^{3)}$ reported a technique that produced long-term survival of cultured adult rat heart cells by using enzymatical and mechanical treatment. However, we could maintain cultures produced by this method for only 2-3 days.

Modification of the method extended the culture period to 5 days. After this period, non-muscle cells (endothelial cells and fibroblasts) proliferated and contaminated the culture. Experiments reported here were carried out in order to remove contamination and prolong culture viability.

\section{Methods}

Our previously reported procedures for producing viable heart cell

From the Second Department of Pathology, Kurume University School of Medicine, Kurume, Japan.

Address for reprint: Kazunari Yamana, M.D., Second Department of Pathology, Kurume University School of Medicine, Asahi-machi 67, Kurume 830, Japan.

Received for publication May 11, 1984.

Manuscript revised July 18, 1984. 
cultures $^{1)}$ (mechanical and enzymatical treatment: $0.25 \%$ trypsin $+0.05 \%$ collagenase) was followed until the third mechanical treatment step. Mechanical treatment was readjusted to $12 \mathrm{rpm}$ from the previous $8 \mathrm{rpm}$, shortening treatment time to $20 \mathrm{~min}$.

Heart tissue fragments were then washed 3 times with $1 \mathrm{ml}$ of saline A and placed in a centrifuge tube. Into the same vial were added a treated enzymatic solution, ${ }^{1)}$ the treated saline A solution and $8 \mathrm{ml}$ Ficoll-Paque (Pharmacia, Lot No. 3088). Following $8 \mathrm{~min}$ centrifugation at $45 \mathrm{G}$ (about $500 \mathrm{rpm} / \mathrm{min}$ ) the supernatant was discarded.

Disaggregated cardiomyocytes were placed in a $35 \mathrm{~mm}$ diameter Falcon petri dish with $2 \mathrm{ml}$ of $20 \%$ FBS and $80 \%$ Eagle's MEM medium (Nissui Seiyaku Co., Ltd., No. 613821). The upper half of medium was immediately exchanged 5 times and the mixture was then incubated in $5 \% \mathrm{CO}_{2}$ and $95 \%$ air at $37^{\circ} \mathrm{C}$. The tissue fragments were then re-treated 6 times with $1 \mathrm{ml}$ of fresh enzyme solution. The upper half of medium was exchanged gently every day.

For observing effects of FBS concentration, disaggregated adult rat cardiomyocytes were cultured for 7 days with $5 \%, 10 \%, 20 \%, 30 \%, 40 \%$ or $60 \%$ FBS and Eagle's MEM solution. Non-muscle cells were then excluded with a hand-made glass needle under a phase contrast microscope, and whole medium was immediately changed.

\section{Results}

Increasing the rotation rate of the apparatus to $12 \mathrm{rpm}$ doubled the number of beating cells. The use of over $70 \%$ Ficoll-Paque decreased the number of beating heart cells to about $10 \%$ after 2 weeks of incubation. Less than $60 \%$ Ficoll-Paque produced longer term cultures. From day 5 onwards, adult rat heart cells in the culture fixed to the bottom of the dish and became flatter. Stable cell beating was observed from day 7 (Fig. 1-A and B).

Electron micrographs of 10 day old cultures showed Z-bands or bundles of myofilaments in separate regions of the cytoplasm of the cells. Mitochondria seemed to retain their original shapes, being distinct from those of other cultured non-muscle cells which were elongated. Cristae had parallel and loose structure (Fig. 2). Cardiomyocytes with arrested beating had damaged cristae and myelin-like figures of degenerated mitochondria (Fig. 3).

Fifty to $60 \%$ of co-cultured adult rat heart cells were actively beating for over 50 days, though most cells did not survive over 2 weeks in the absence of non-muscle cells. In addition, cardiomyocytes co-cultured for 20 to 30 days only survived up to 24 hours if non-muscle cells were excluded from 


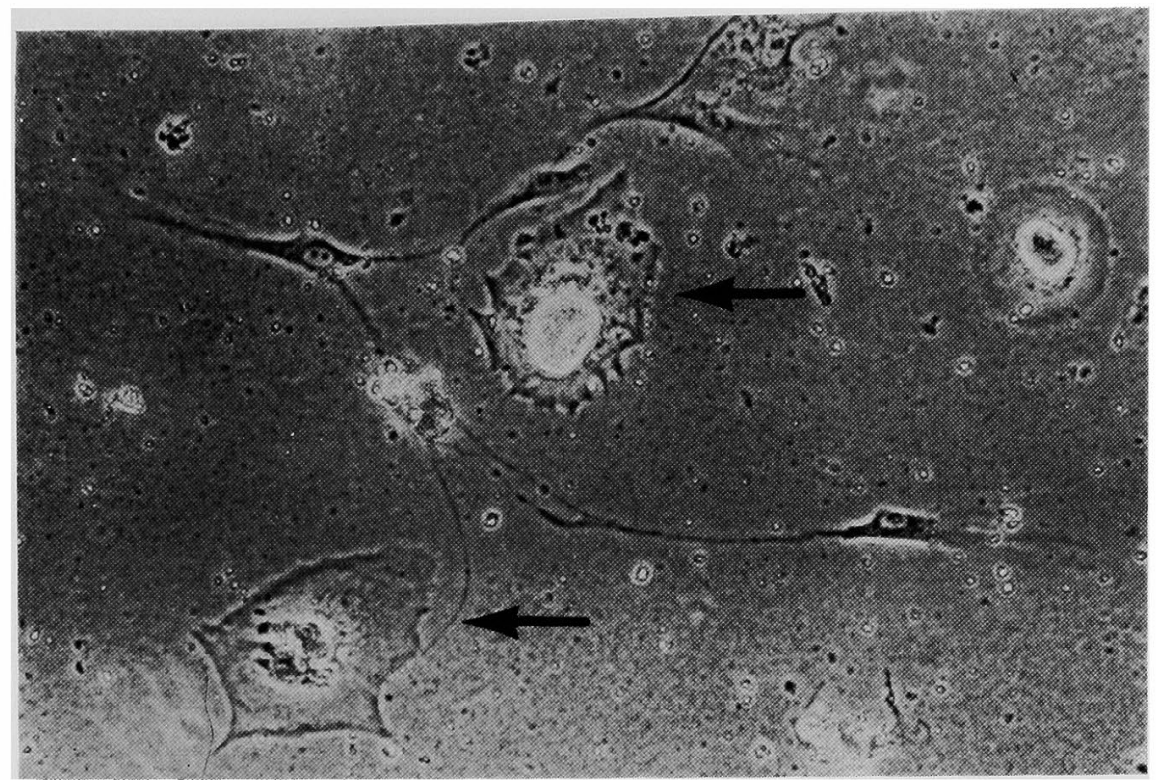

A

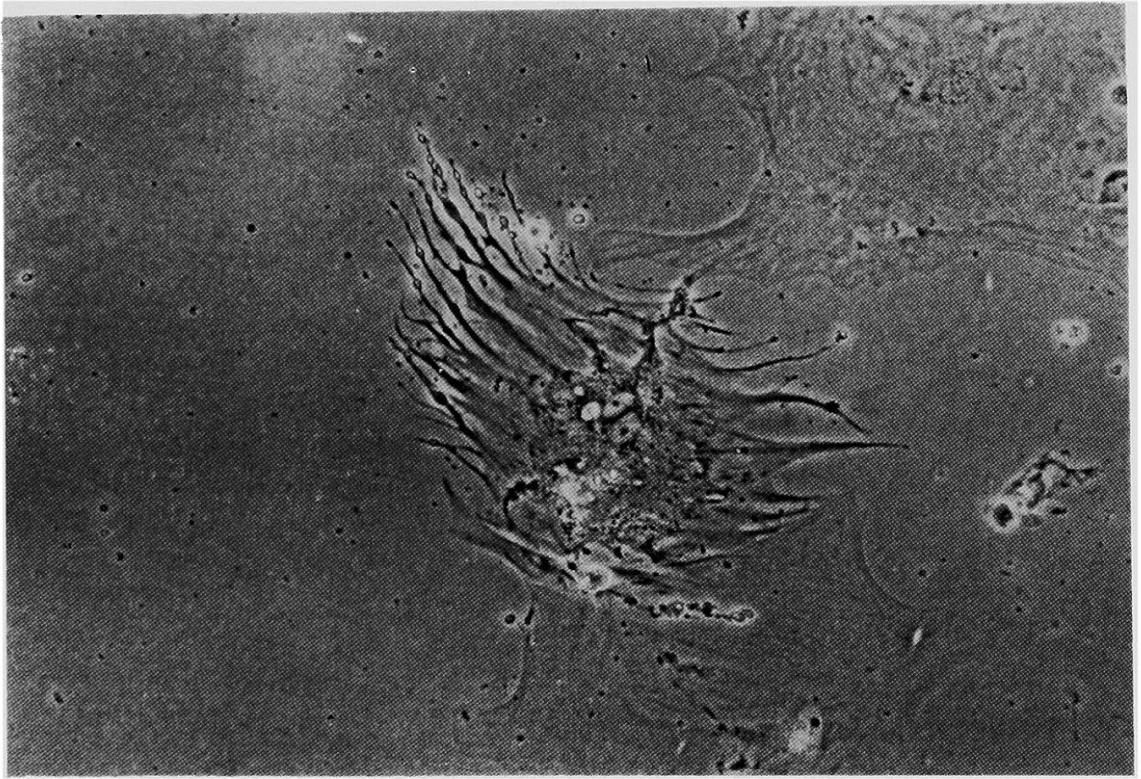

Fig. 1-A (upper). Phase-contrast micrograph showing a 7 day culture of adult rat heart cells (arrow). Their morphology differs from that of nonmuscle cells. $(\times 920)$

1-B (lower). A heart cell cultured for 21 days is in the center; it has two nuclei and branch-like foot processes.

their surroundings (Fig. 4-A, B and C).

Cultured cardiomyocytes stopped beating and died within 12 hours without FBS, within 24 to 48 hours in 5\% FBS and within 7 days in $10 \%$ 


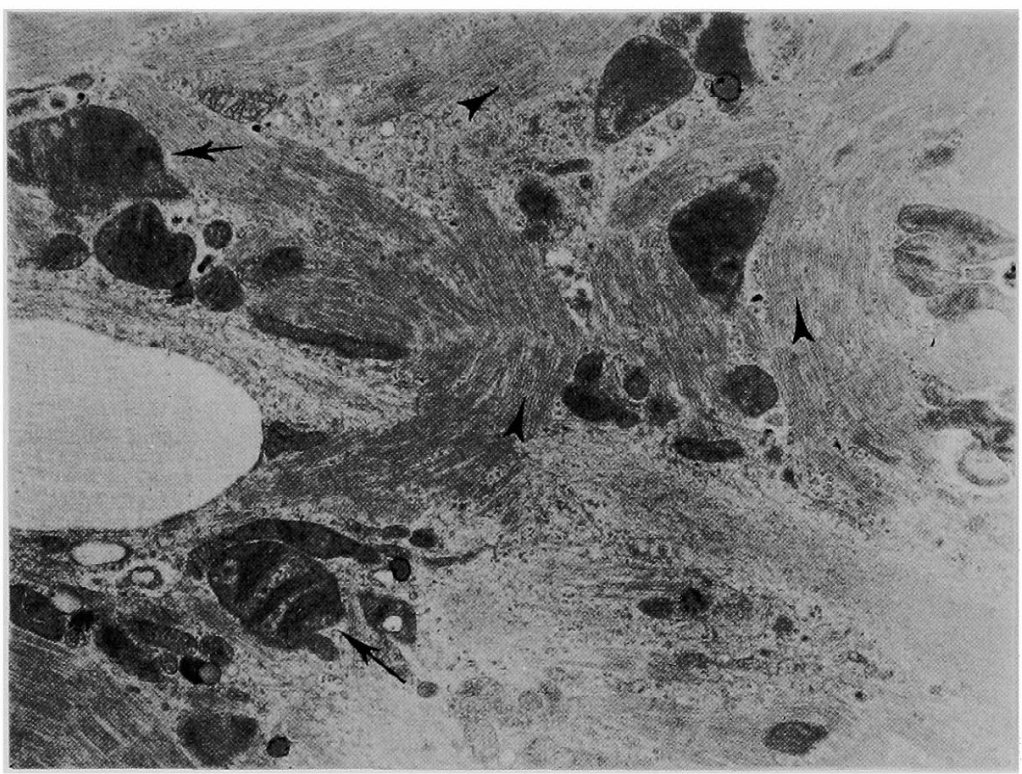

Fig. 2. Horizontal section of an electron micrograph of an adult rat heart cell after 10 days in culture. Arrowheads show Z-bands and arrows show mitochondria which have parallel and loose structure of cristae. $(\times 48,000)$

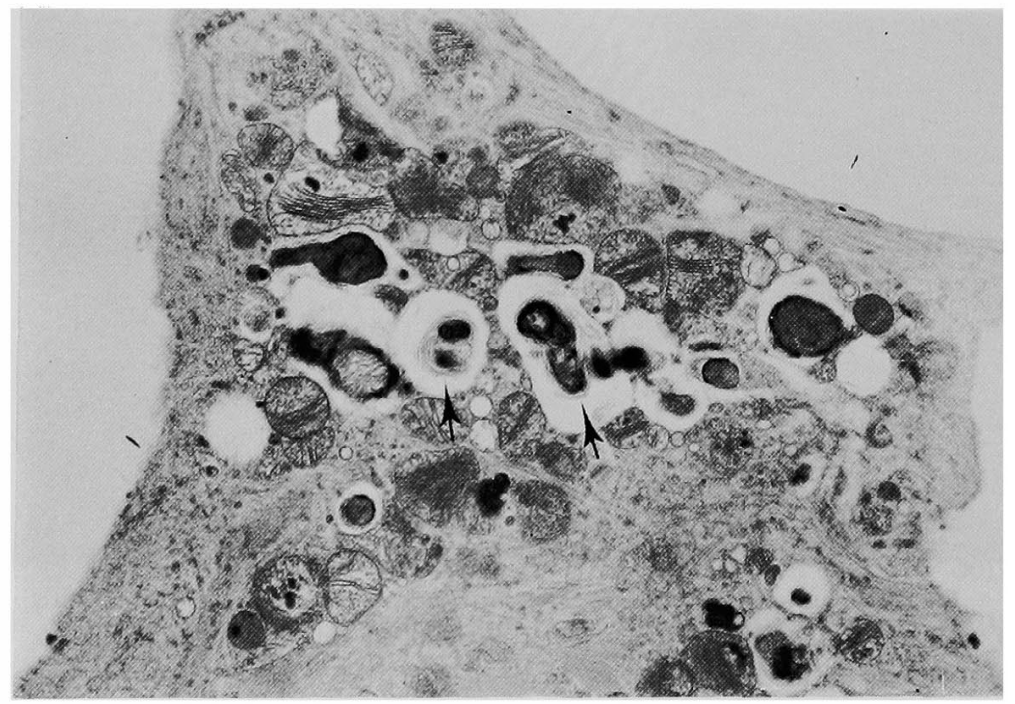

Fig. 3. Electron micrograph of a cardiomyocyte with arrested beating showing injured mitochondria with myelin-like figures (arrows). ( $\times 48,000)$

FBS. FBS concentrations greater than $20 \%$ resulted in long-term survival of cardiomyocytes, and they fixed to the bottom of dish from day 3 of culture in over $40 \% \mathrm{FBS}$. 
A
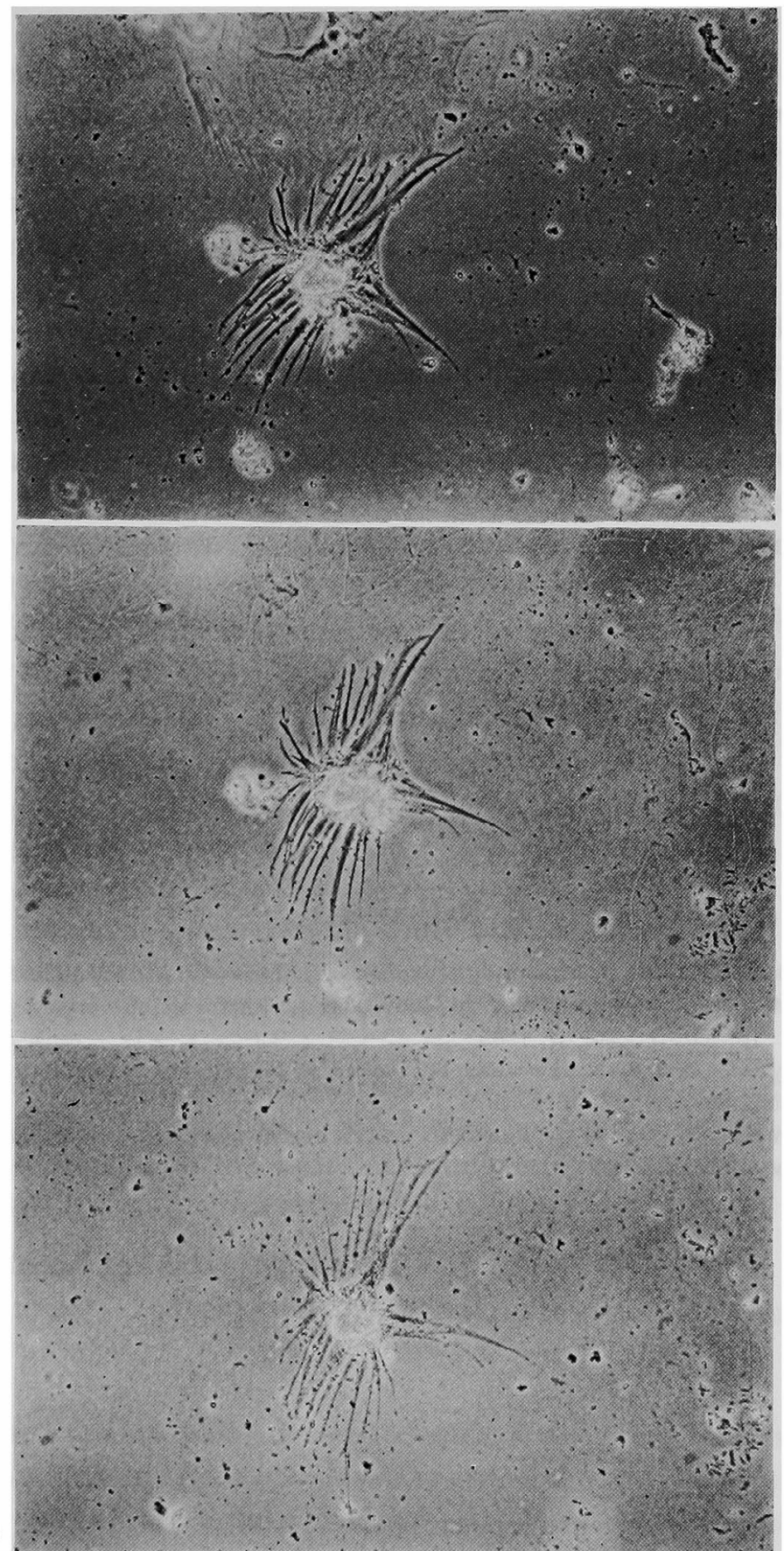

Fig. 4-A (top). Phase-contrast micrograph showing a cardiomyocyte after 30 days in culture in the center and a non-muscle cell in the upper area. $(\times 460)$ 4-B (center). The same beating cell as in Fig. 4-A at 20 hours after exclusion of non-muscle cell. $(\times 460)$ 4-C (bottom). The same cell in Fig. 4-B at 48 hours after exclusion of non-muscle cell. Severe degeneration such as numerous vacuolation is seen in cytoplasm. 


\section{Discussion}

Cultured adult rat heart cells could only survive a few days in Medium 199. However, frequent medium exchange from the earliest possible stage could keep them beating for 5 days. This fact indicated the importance of complete exclusion of all remaining enzymes and toxins originating from cell debris.

Ficoll-Paque, employed here for exclusion of non-muscle cells, is harmful to cardiomyocytes. This necessitated frequent medium changes which eliminated all traces of this substance. On the other hand, such frequent medium change reduced the number of beating cells in the culture. Optimal FicollPaque concentrations were approximately $60 \%$.

Adult rat heart cells survived longer when cultured in the presence of non-muscle cells. In view of this and the findings it seems likely that nonmuscle heart cells produce and excrete unknown factors necessary for survival of cultured heart cells. In addition, a $20 \%$ FBS content in the medium was found to be sufficient for the culture's success. These modified techniques prolong the survival of cultured adult rat heart cells which can now be employed in other studies.

\section{REFERENGES}

1. Yamana K, Kinoshita T, Nakano R, Tokunaga $O$, Morimatsu M, Nakashima T: Adult rat heart cell culture: the morphological study of tissue fragments on various environments in culture. Jpn Heart J 26: 81, 1985

2. Vahouny GV, Wei R, Starkweather R, Davis C: Preparation of beating heart cells from adult rats. Science 167: 1616, 1970

3. Jacobson SL: Culture of spontaneously contracting myocardial cells from adult rats. Cell Structure and Function 2: 1, 1977 